Published in final edited form as:

Curr Top Microbiol Immunol. 2013 ; 372: 259-284. doi:10.1007/978-3-642-38919-1_13.

\title{
Live-Attenuated Respiratory Syncytial Virus Vaccines
}

\author{
Ruth A. Karron, \\ Center for Immunization Research, Department of International Health, Bloomberg School of \\ Public Health, Johns Hopkins University, Baltimore, MD, USA \\ Ursula J. Buchholz, and \\ Laboratory of Infectious Diseases, National Institute of Allergy and Infectious Diseases, National \\ Institutes of Health, Bethesda, MD, USA
}

\section{Peter L. Collins}

Laboratory of Infectious Diseases, National Institute of Allergy and Infectious Diseases, National Institutes of Health, Bethesda, MD, USA

Ruth A. Karron: rkarron@jhsph.edu

\begin{abstract}
Live-attenuated respiratory syncytial virus (RSV) vaccines offer several advantages for immunization of infants and young children: (1) they do not cause vaccine-associated enhanced RSV disease; (2) they broadly stimulate innate, humoral, and cellular immunity, both systemically and locally in the respiratory tract; (3) they are delivered intranasally; and (4) they replicate in the upper respiratory tract of young infants despite the presence of passively acquired maternally derived RSV neutralizing antibody. This chapter describes early efforts to develop vaccines through the classic methods of serial cold-passage and chemical mutagenesis, and recent efforts using reverse genetics to derive attenuated derivatives of wild-type (WT) RSV and to develop parainfluenza vaccine vectors that express RSV surface glycoproteins.
\end{abstract}

\section{Introduction}

Efforts to develop live-attenuated RSV vaccines began in response to the tragic results of studies of a formalin-inactivated pediatric RSV vaccine in the 1960s. This vaccine was poorly protective and, in RSV-naïve recipients, primed for enhanced disease upon subsequent natural RSV infection (see chapter by P.L. Collins et al., this volume). In contrast, live RSV vaccine viruses do not appear to prime for enhanced RSV disease based on studies in experimental animals (Waris et al. 1997), and the general observation that community-acquired infection followed by re-infection is not associated with enhanced disease. This notion was confirmed by studies of several live-attenuated RSV vaccine candidates involving over 380 RSV-naïve infants and children, none of whom showed evidence of enhanced disease after natural infection with WT RSV (Wright et al. 2007). Live-attenuated vaccines are the only type of RSV vaccines that have been demonstrated to be safe in RSV-naïve recipients. 
Live-attenuated RSV vaccines are administered intranasally, which offers three advantages: (1) replication in the upper respiratory tract and immunogenicity even in the presence of passively acquired, maternally derived serum neutralizing antibody, which usually is present in young infants (see below), (2) induction of local mucosal immunity, which is important in restricting replication of respiratory viruses, and (3) needle-free administration. In general, live vaccines broadly stimulate innate, cellula, and humoral immunity (Collins and Murphy 2005; Murphy and Collins 2002), and studies of influenza vaccines in infants and children indicate that live vaccines induce a broader, more effective, and possibly a more durable response than subunit vaccines (Ambrose et al. 2011, 2010; Belshe et al. 2007; Hoft et al. 2011).

One potential limitation to a live-attenuated RSV vaccine is that, as is typical for liveattenuated vaccines in general, a low-to-moderate level of vaccine virus replication is necessary to achieve an optimal immune response. This is probably because virus replication provides pathogen-associated molecular patterns (PAMPs) that stimulate innate immunity and antigens that stimulate adaptive immunity via MHC class I and MHC class II presentation pathways. On the other hand, the level of replication of live-attenuated RSV vaccines is generally inversely correlated with attenuation (Karron et al. 2005, 1997; Wright et al. 1982, 2000, 2006). While RSV vaccine candidates have been developed that are attenuated and highly restricted in replication (Karron et al. 2005; Wright et al. 2006) it has not yet been demonstrated that these are sufficiently immunogenic to provide effective protection against WT RSV. New strategies that capitalize on our understanding of viral replication mechanisms may help to overcome these limitations. Another limitation is the notorious instability of the virus itself, which likely will complicate vaccine production, storage and usage in resource-challenged settings.

The primary targets for a live-attenuated RSV vaccine are infants and young children. Since the peak of hospitalization for RSV disease occurs at 2-4 months of age, one proposed strategy is to immunize very early in infancy, beginning at 1-2 months of age. However, a number of factors complicate RSV vaccination of the young infant, including immunologic immaturity, the immunosuppressive effects of maternal antibodies, and the natural occurrence of events such as apnea and sudden infant death syndrome that might be perceived to be vaccine related. Therefore, an alternative strategy would be to begin immunization somewhat later, at approximately 4-6 months of age. About $40 \%$ of hospitalizations and $75 \%$ of outpatient visits for RSV disease occur in infants and young children over 6 months of age (Hall et al. 2009). Thus, this approach would reduce the considerable burden of pediatric RSV disease that occurs beyond early infancy (Hall et al. 2009), and might reduce transmission in the community.

Live-attenuated RSV vaccines are evaluated for replication, tolerability, and immunogenicity in Phase I studies by age de-escalation with a transition from RSVexperienced to RSV-naïve study groups. Studies in adults are typically open-label, whereas studies in children are placebo-controlled to allow for evaluation in the context of the myriad community-acquired respiratory and febrile illnesses frequently observed in young children. Each new vaccine is typically evaluated sequentially in (1) adults, presumed to be RSV-seropositive ( 15 subjects); (2) RSV-seropositive children aged 12-59 months ( 10 
and $\sim 5$ vaccine and placebo recipients, respectively); and (3) RSV-seronegative children aged 6-24 months ( 20 and $\sim 10$ vaccine and placebo recipients, respectively). If a vaccine candidate is sufficiently attenuated in RSV-seronegative children, it may also be evaluated in RSV-naïve infants aged 1-3 months ( 20 and $\sim 10$ vaccine and placebo recipients, respectively). This stepwise strategy has proved to be a careful method for the evaluation of vaccine safety; it is described further in Sect. 5.

Over the past 35 years, several types of live-attenuated RSV vaccines have been described, including biological and recombinant derivatives of WT RSV, as well as replicationcompetent parainfluenza virus vectors expressing one or both of the RSV fusion (F) and heavily glycosylated (G) surface glycoproteins, which are the two neutralization and major protective RSV antigens. Most of these experimental vaccines have been made using RSV antigenic subgroup A viruses, usually the A2 strain. This chapter will describe past and current efforts to develop live-attenuated RSV vaccines suitable for administration to RSVnaïve infants and children. The live-attenuated pediatric RSV vaccines currently under evaluation are not being considered for use in adults because they are over-attenuated in RSV-experienced individuals (Gonzalez et al. 2000; Wright et al. 2006).

\section{Live-Attenuated Vaccines: Biologically Derived RSV Strains}

The first live-attenuated candidate RSV vaccines (given in Table 1) were developed either by repeated passage at low temperature to yield cold-passaged ( $c p$ ) RSV (Friedewald et al. 1968) or by chemical mutagenesis to yield temperature-sensitive ( $t s)$ mutants designated $t s-1$ or $t s-2$ (Gharpure et al. 1969; Wright et al. 1982, 1976) and $t s-1 \mathrm{~A}, \mathrm{~B}$, and C (McKay et al. 1988; Pringle et al. 1993). The hypothesis underlying these efforts was that mutations which rendered the virus temperature-sensitive, i.e., less able than WT RSV to replicate at temperatures $337^{\circ} \mathrm{C}$, would produce vaccine viruses that would preferentially replicate in the cooler upper respiratory tract but be restricted in replication in the lower respiratory tract, thereby diminishing the risk of lower respiratory tract illness (LRI) associated with vaccine virus replication. As described below, the $c p$ mutations were later mapped to five missense mutations in the nucleoprotein $(\mathrm{N}), \mathrm{F}$ glycoprotein, and polymerase (L) protein genes, whereas the mutations present in the early $t s$ mutants have not been directly mapped and identified. Both $c p$ RSV and $t s$ - 1 were underattenuated in RSV-seronegative children, and isolates that had lost the $t s$ phenotype were recovered from children administered the $t s-1$ vaccine (Table 1; Kim et al. 1973; Wright et al. 1976). In contrast, $t s-2$ was overattenuated and replicated poorly in RSV-seronegative children (Table 1; Wright et al. 1982). $t s-1 \mathrm{~A}, \mathrm{~B}$, and $\mathrm{C}$ were only administered to adult subjects. $t s-1 \mathrm{~A}$ and $\mathrm{B}$ were insufficiently attenuated in adults; $t s-1 \mathrm{C}$ was satisfactorily attenuated in adults but was not evaluated further (Table 1; Pringle et al. 1993).

In the mid-1990s, additional efforts were made to develop a live-attenuated RSV vaccine through chemical mutagenesis of $c p R S V$ followed by screening for temperature sensitivity. Several RSV A2 cpts mutants were identified, including candidate vaccines designated as cpts248/955, cpts530/1009, and cpts248/404 (Table 1; Crowe et al. 1994, 1995; Firestone et al. 1996). cpts248/955 and cpts530/ 1009 were each sequentially evaluated in adults, RSVseropositive children, and RSV-seronegative children. While both of these vaccines were 
attenuated in adults and seropositive children, they were insufficiently attenuated in seronegative children: replication of cpts248/955 was associated with LRI (wheezing) in one child, and the cpts530/1009 vaccine was transmitted from a seronegative vaccinee to a placebo recipient (Karron et al. 1997). cpts248/404 was highly attenuated in RSVseropositive and -seronegative children, but was associated with nasal congestion in 1-2 month-old infants (Wright et al. 2000). Although cpts248/404 was insufficiently attenuated for young infants, these studies demonstrated that an intranasally administered liveattenuated vaccine could replicate in the presence of maternally derived RSV serum neutralizing antibody, an important principle for future vaccine development.

During this period, efforts were also made to develop a live-attenuated RSV B candidate vaccine. The most noteworthy candidate was RSV $c p-52 \mathrm{~B}$, a live-attenuated virus derived by serial passage of WT RSV B1 virus at low temperature. This virus was replication competent in vitro, but was over-attenuated in seronegative children and was subsequently found to contain a large deletion that prevented expression of the $\mathrm{SH}$ and $\mathrm{G}$ proteins (Karron et al. 1997). The over-attenuation and lack of G expression made RSV cp-52B unsuitable as a vaccine candidate.

Attempts to further attenuate the promising cpts248/404 virus by an additional round of mutagenesis and selection were unsuccessful. It became clear that the conventional methods of vaccine development such as cold-passage and chemical mutagenesis were too unpredictable and labor-intensive to be practicable for RSV.

\section{Attenuated RSV Strains Produced by Reverse Genetics}

In 1995, a reverse genetic system for producing complete infectious RSV strain A2 was developed, thus providing the capability of inserting pre-determined mutations into live RSV via cloned cDNA. All subsequent vaccine candidates have been produced by reverse genetics (Table 2).

Reverse genetics has a number of advantages for developing attenuated strains (Collins and Murphy 2005; Murphy and Collins 2002). Reverse genetics can directly identify and characterize attenuating mutations in existing attenuated strains (Bartlett et al. 2005; Firestone et al. 1996; Juhasz et al. 1999; Nolan et al. 2007; Whitehead et al. 1998a, b) and also can produce novel mutations not found in biologically derived strains (Bermingham and Collins 1999; Luongo et al. 2013; Teng et al. 2000; Whitehead et al. 1999). The resulting well-characterized attenuating mutations from this menu can then be assembled in desired combinations to produce live-attenuated candidate vaccines with a range of phenotypes and properties (Bartlett et al. 2005; Karron et al. 2005; Luongo et al. 2012, 2013; Nolan et al. 2007; Whitehead et al. 1999; Wright et al. 2006). However, the resulting level of attenuation cannot be predicted precisely, since the aggregate attenuating effect is not always precisely the sum of the individual mutations (Karron et al. 2005), and mutations are sometimes incompatible (Whitehead et al. 1999). The defined attenuating mutations in these viruses can readily be monitored for stability during vaccine manufacture and use, and the significance of chance mutations that may occur during virus replication can be assessed. Vaccine strains can be adjusted, such as by further attenuation in response to clinical data (Karron et al. 
2005), or by updating the $\mathrm{F}$ and $\mathrm{G}$ surface antigens in response to changes in circulating stains. Amino acid substitutions can be manipulated to reduce the frequency of mutations that lead to loss of attenuation (Luongo et al. 2013, 2009). Producing virus from cDNA provides a vaccine seed with a short, well-documented passage history (Surman et al. 2007), which reduces the possibility of contamination by adventitious agents. Cloned cDNA provides a stable seed from which virus can be regenerated if necessary.

\subsection{Attenuating Point Mutations}

A number of attenuating mutations useful for constructing recombinant RSV vaccine strains were identified by analysis of the previously mentioned biological $c p$ RSV mutant and six of its biological $t s$ derivatives, namely cpts 248 , cpts248/ 404, cpts248/955, cpts530, cpts530/1009, and cpts530/1030 (Juhasz et al. 1999; Whitehead et al. 1998a, b; 1999). Each biological virus was completely sequenced, and attenuating mutations were confirmed by introduction into WT recombinant virus and phenotypic analysis. It was useful to identify attenuating mutations in existing biological mutants known to replicate efficiently in vitro, because these mutations should be compatible with efficient growth in cell culture that is essential for vaccine manufacture. It also was desirable to identify $t s$ mutations since, as noted above, these preferentially restrict virus replication at higher temperatures present in the lower respiratory tract.

Using reverse genetics, we found that the attenuation phenotype of $c p R S V$ was specified by five amino acid substitutions in three proteins: N (V267I), F (E218A and T523I), and L (C319Y and H1690Y). Analysis of the other six biological $t s$ viruses yielded a total of six independent mutations that each conferred a $t s$ attenuation phenotype. Five of these were amino acid substitutions in the $\mathrm{L}$ protein (which were named based on virus number rather than sequence position): "955” (N43I), "530" (F521L), "248” (Q831L), “1009” (M1169 V), and "1030" (Y1321 N). The sixth mutation (called "404") was a single nucleotide change in the gene-start signal of the M2 gene (GGGGCAAATA to GGGGCAAACA, mRNA-sense). This latter mutation is somewhat of a surprise: while it is easy to imagine how a point mutation in a protein could render it $t s$, it remains unclear how a nucleotide substitution in a short circumscribed transcription signal confers a $t s$ phenotype. Since these six $t s$ mutations were found in the viral polymerase or in a gene start (GS) transcription signal, they presumably act by reducing viral RNA synthesis at restrictive temperature.

\subsection{Attenuating Gene Deletions}

As another means of attenuating RSV, we identified five different RSV genes or ORFs (the $\mathrm{NS} 1, \mathrm{NS} 2, \mathrm{SH}$, and G genes and the M2-2 ORF) that could be deleted individually, and in some combinations, with the effect of restricting viral replication, especially in vivo.

Deletion of $\mathrm{G}$ was not considered further as an attenuating mutation because antibodies to RSV G contribute to neutralization and protection (Connors et al. 1991; Zhang et al. 2010). The $\Delta \mathrm{NS} 1$ and $\Delta \mathrm{M} 2-2$ mutations each conferred a 500- to 1000 -fold restriction in virus replication in seronegative chimpanzees (Teng et al. 2000). This approximates the level of attenuation thought to be necessary for a live RSV vaccine, and thus either might be an appropriate stand-alone mutation. The $\Delta \mathrm{SH}$ and $\triangle \mathrm{NS} 2$ mutations were associated with a 10 fold and 100-fold restriction of virus replication in chimpanzees (Whitehead et al. 1999), 
respectively, and thus would need to be combined with other mutations in order to make a suitably attenuated vaccine candidate. Since the NS1 and NS2 proteins are antagonists for type I interferon (IFN) production and signaling (see chapter by S. Barik, this volume), the restriction of viral replication observed for these deletion viruses presumably is due at least in part to increased IFN responses and resulting increased antiviral effect. Increased IFN responses may have an adjuvant effect that may increase vaccine immunogenicity (Valarcher et al. 2003). However, the $\Delta$ NS1 mutant also was found to cause increased apoptosis during replication in vitro, resulting in reduced viral yields (Bitko et al. 2007), and it is not clear whether the $\mathrm{NS} 1$ virus can be propagated sufficiently well for vaccine purposes. The M2-2 protein plays a role in regulating viral RNA synthesis: deletion of M2-2 results in decreased synthesis of antigenomic and genomic RNAs, which presumably is the basis for attenuation, and in increased gene transcription, which results in increased expression of the viral proteins including the viral neutralization and protective antigens (Bermingham and Collins 1999). This might increase vaccine immunogenicity, a particularly important consideration for infant immunization. The basis of attenuation conferred by the SH deletion may involve increased tumor necrosis factor expression (Fuentes et al. 2007), but is incompletely understood. An important advantage of attenuation based on the deletion of an entire gene is that it should be highly refractory to genetic reversion or compensatory mutation.

\subsection{Progressive Attenuation by Reverse Genetics Yields a Promising Candidate}

As noted, the biological cpts248/404 virus appeared to be a promising candidate based on studies in seronegative children but was insufficiently attenuated in 1-2 month-old infants (Wright et al. 2000). Therefore, efforts were made to create a recombinant derivative that is more attenuated. The biological virus contains three attenuating mutations, namely $\mathrm{cp}$ (note that "cp" refers to a set of 5 amino acid substitutions in the N, F, and L proteins, as already noted), 248, and 404. The first recombinant derivative contained these three mutations combined with deletion of the SH gene, yielding rA2cp248/404 $\Delta \mathrm{SH}$ (Table 2). However, this virus was not more attenuated than its cpts248/404 parent in seronegative children (Karron et al. 2005), indicating that inclusion of the $\Delta \mathrm{SH}$ mutation in this background did not confer additive attenuation. Addition of the 1030 mutation resulted in rA2cpts248/404/1030 $\Delta \mathrm{SH}$ (Fig. 1; Table 2), which had increased temperature sensitivity (i.e., rA2cpts $248 / 404 / 1030 \Delta \mathrm{SH}$ did not form plaques at $35-36{ }^{\circ} \mathrm{C}$, whereas rA2cp248/404 $\Delta \mathrm{SH}$ did not form plaques at $38{ }^{\circ} \mathrm{C}$ ) and was at least 10 - fold more restricted in replication in seronegative children than cpts248/404 (Karron et al. 2005). The vaccine was well-tolerated in 1-2 month-old infants, was moderately immunogenic, and was protective against 'challenge' with a second dose of vaccine (Table 2; Karron et al. 2005).

Although rA2cp248/404/1030 $\Delta \mathrm{SH}$ appeared to have achieved an appropriate level of attenuation, analysis of vaccine virus isolates recovered from RSV-naïve children provided evidence of phenotypic instability: more than one-third of the isolates exhibited a $1-2{ }^{\circ} \mathrm{C}$ upward shift in temperature-sensitivity, and sequence analysis identified instances of loss of either the 248 or 1030 mutation, with loss of the latter being 4-fold more frequent.

However, these partial revertants retained four of five attenuating elements, and replication of these partial revertants was not associated with enhanced replication or clinical illness in 
the small numbers of children evaluated. While this degree of genetic instability might be acceptable, larger studies to more fully evaluate the potential for reversion and for transmission to susceptible contacts would be needed. A second version of this virus was made in which the codon for the 248 mutation was changed from L(CTG) to L(TTA) in an effort to increase its genetic stability, since TTA requires at least two nucleotides to revert to the WT assignment of glutamine (CAA or CAG). This virus, called MEDI-559 (Fig. 1;

Table 2), contains 35 other silent nucleotide changes that are thought to be inconsequential. It presently is in Phase I/IIa studies to evaluate safety, stability, and immunogenicity in a larger number of RSV-seronegative children (ClinicalTrials.gov identifier NCT00767416).

\subsection{Improvements in Genetic Stability Using Reverse Genetics}

We also have worked to increase the genetic and phenotypic stability of the " 248 " and "1030" mutations in MEDI-559. We used reverse genetics to systematically analyze all possible amino acid assignments at the 248 and 1030 loci to identify more stable alternatives. Using this approach, each amino acid assignment is evaluated phenotypically to identify all possible attenuating versus WT-like assignments. Attenuating assignments are then examined to identify codons that differ from all possible codons for WT-like assignments by 2 or, preferably, 3 nucleotides (Luongo et al. 2012, 2009). This is based on the premise that the frequency of loss of attenuation requiring a single nucleotide change will approximate the viral mutation rate of $\sim 10^{-4}$, whereas loss of attenuation requiring two or three nucleotide changes will have rates of $\sim 10^{-8}$ and $10^{-12}$, respectively, and thus will be much less frequent. For the " 248 " locus (Q831L in the L protein), we were unable to find an alternative attenuating amino acid or codon that would require two or three nucleotide changes. However, we found differences in stability among the available leucine codonswhich was somewhat surprising - and thus identified a better choice at this position, namely L(TTG) (Luongo et al. 2009). For the "1030" locus (Y1321 N in the L protein), at which loss of attenuation was more frequent, we did identify more stable alternatives, including $\mathrm{K}(\mathrm{AAA}), \mathrm{G}(\mathrm{GGA}), \mathrm{E}(\mathrm{GAA})$, and $\mathrm{E}(\mathrm{GAG})$ (Luongo et al. 2012). Increased stability was confirmed by in vitro "stress tests", in which candidate viruses are passaged at progressively higher temperatures to favor outgrowth and detection of mutants with shifts in the $t s$ phenotype. We also found that attenuation conferred by the 1030 mutation could be partly abrogated by a second-site, compensatory S1313C change in the L protein. However, this compensatory mutation could be prevented by changing the naturally occurring S(AGC) codon to S(TCA), which requires two rather than one nucleotide substitutions to change to cysteine. Though the process of genetic stabilization is complex and labor-intensive, systematic analysis using reverse genetics can provide new RSV candidates with stabilized attenuating mutations.

One such candidate is designated RSV cps2 (Table 2; Luongo et al. 2012). RSV cps2 is a modified version of MEDI-559 that contains stabilized 248 and 1030 mutations: namely, 831L[TTG] and $1321 \mathrm{~K}$ [AAA], respectively, with the additional assignment of 1313S[TCA] to prevent the compensatory mutation noted above. This results in a total of five nucleotide changes and one amino acid change. RSV cps 2 was confirmed to be indistinguishable from MEDI-559 with regard to the level of replication in RSV-seronegative chimpanzees, and the virus is being prepared for clinical evaluation as a stabilized version of MEDI-559. 
We also investigated the possibility of gaining increased genetic stability by deleting one or more codons in the $\mathrm{L}$ gene. We focused on the sites of the amino acid substitutions identified in the biological mutants already described: 248, 530, 955, 1009, and 1030 . However, deletions at or near these sites could not be recovered. Surprisingly, we found that codon 1313, which was already mentioned as the site of a compensatory mutation, could be deleted. This yielded a virus that was substantially attenuated, was $t s$, replicated with WTlike efficiency at the permissive temperature of $32{ }^{\circ} \mathrm{C}$, and was stable during in vitro stress tests (Luongo et al. 2013). A virus containing the codon 1313 deletion combined with deletion of the NS2 gene is currently being developed as a new RSV vaccine candidate (RSV $\Delta$ NS2 $\Delta 1313$ I1314L, see below).

\subsection{Other Promising Vaccine Candidates}

It may be possible to increase the immunogenicity or decrease the reactogenicity of RSV vaccine viruses by manipulation or deletion of RSV proteins involved in immune evasion (e.g., NS1 and NS2) or the regulation of RSV gene expression (e.g., M2-2). One strategy combined the NS2 deletion with various point mutations. The cp and $\Delta \mathrm{NS} 2$ mutations were combined to create $\mathrm{rA} 2 \mathrm{cp} \Delta \mathrm{NS} 2$, which was evaluated in adults as a candidate vaccine to boost immunity in RSV-experienced individuals such as the elderly, and was also evaluated as a potential pediatric vaccine in RSV-seropositive children (Table 2). While this virus was over-attenuated in adults, it was insufficiently attenuated in RSV-seropositive children to permit evaluation in RSV-seronegative children; therefore, it would be unsatisfactory in either RSV-experienced or -naïve recipients and was not evaluated further (Wright et al. 2006).

To achieve a greater level of attenuation necessary for a pediatric vaccine, the $\Delta$ NS2 mutation was combined with 2 other sets of attenuating mutations, namely (i) the cp, 248, and 404 mutations, to yield rA2cp248/404 $\Delta$ NS2 and (ii) the cp, 530, and 1009 mutations, to yield rA2cp530/1009 $\Delta$ NS2 (Table 2). Each of these viruses was highly attenuated in adults and seropositive children, but was over-attenuated in seronegative children (Wright et al. 2006). More recently, the $\Delta$ NS2 mutation was combined with the newly identified $\Delta 1313$ codon deletion described above, yielding the RSV $\Delta$ NS2 $\Delta 1313$ virus (Luongo et al. 2013). Stress tests of this virus showed that it acquired a second-site mutation I1314T that partly abrogated the $t$ s phenotype of the $\Delta 1313$ mutation (Luongo et al. 2013). However, when the native isoleucine codon was replaced with one for leucine, the resulting virus was stable during passage at $37^{\circ} \mathrm{C}$ (Luongo et al. 2013). This virus replicated in seronegative chimpanzees to a level similar to that of MEDI-559 and RSV cps2, and thus it appears to be suitable for clinical evaluation as a candidate pediatric vaccine (Table 2).

A third type of RSV vaccine virus that is currently being tested clinically contains a deletion of most of the M2-2 ORF (Table 2). As noted, the $\Delta \mathrm{M} 2-2$ mutant exhibits reduced RNA replication and increased gene transcription and antigen production, which may provide for increased immunogenicity despite highly restricted replication. This virus was highly attenuated in adults and seropositive children, and presently (January 2013) is being studied in seronegative children. 


\subsection{Summary of Current Live-Attenuated RSV Vaccine Strains}

Four promising candidate viruses representing several different attenuation strategies are presently being evaluated clinically or being prepared for clinical evaluation. MEDI-559 (currently being evaluated in seronegative children, 2013) and RSV cps2 (being prepared for evaluation in seronegative children in 2013) are highly $t s$ and are attenuated mainly by point mutations affecting RNA synthesis. The mechanisms of action of the various mutations that affect RNA synthesis are generally not known, although the 530 and 1009 mutations were studied in a mini-replicon system and appeared to affect both transcription and RNA replication, and the latter mutation appeared to increase the frequency of read through transcription (Juhasz et al. 1999). RSV MEDI $\triangle$ M2-2 (currently being evaluated in seronegative children, 2013) is not $t s$ and is attenuated by deletion of the regulatory M2-2 protein. RSV $\Delta$ NS2 $\Delta 1313 I 1314 \mathrm{~L}$ (currently being evaluated in seropositive children, 2013) is moderately $t s$ and combines two highly stable deletion mutations involving the NS2 IFN antagonist protein and codon 1313 in the L polymerase protein.

\subsection{Other Efforts to Develop a Recombinant Live-Attenuated RSV vaccine}

Bovine RSV (BRSV) was considered as a potential vaccine against human RSV because the two viruses are related antigenically, and BRSV was thought to be attenuated in primates.

However, BRSV was over-attenuated and poorly immunogenic in seronegative chimpanzees (Buchholz et al. 2000). In an attempt to increase its levels of replication and immunogenicity, a recombinant version of BRSV was modified in which the $\mathrm{G}$ and $\mathrm{F}$ genes were replaced by their human RSV counterparts. However, this chimeric virus remained over-attenuated and insufficiently immunogenic in chimpanzees (Buchholz et al. 2000). Various other combinations of bovine and human RSV genes also have been evaluated (our unpublished data). A chimeric virus consisting of the human RSV backbone in which the $\mathrm{P}$ gene was swapped with that of BRSV yielded a promising level of attenuation in chimpanzees (unpublished data), but this virus has yet to be further evaluated.

The RSV L protein was subjected to scanning mutagenesis in which charged residues were changed to alanine residues (Tang et al. 2002). However, this did not yield particularly promising mutations, e.g., mutations that did not restrict virus replication under permissive conditions in vitro (necessary for vaccine manufacture) but were substantially attenuating in vivo.

It may be desirable to include a subgroup B (RSV-B) component in an RSV vaccine, since cross-protection between the two antigenic subgroups is incomplete. One strategy is to express the RSV-B G protein from an added gene in the subgroup A backbone, making a virus that is bivalent with respect to $\mathrm{G}$, the more divergent of the two major RSV protective antigens $F$ and $G$ (Jin et al. 1998). A second strategy is to replace the $F$ and $G$ genes of recombinant RSV-A with their counterparts from RSV-B (Whitehead et al. 1999). Since F and $\mathrm{G}$ are the major protective antigens, this produces an $\mathrm{AB}$ chimeric virus that is predominantly a vaccine against RSV-B and would need to be paired with a separate RSV-A vaccine. These two approaches have the advantage of being able to directly use attenuated RSV-A backbones in developing an RSV-B vaccine: thus, when a suitably attenuated RSVA backbone is identified, the glycoprotein addition or glycoprotein swap would 
expeditiously provide an RSV-B component. As a third approach, a reverse genetics system was developed for RSV-B that can be used to prepare attenuated RSV-B strains, such as by incorporating attenuated mutations identified for RSV-A. This approach has the advantage of providing the complete set of RSV-B antigens, rather than only $\mathrm{G}$ and F.

Continuing pre-clinical work on vaccine development should also consider additional objectives, such as improved growth in cell culture, improved immunogenicity, and reduced reactogenicity. A modest increase in growth in cell culture (accompanied by modestly decreased, rather than increased, replication in vivo) was observed with deletion of the SH gene. It may be that further reduction in genome size, such as by the deletion of nonessential sequence, would increase growth in cell culture, improving manufacture. We have already noted that deletion of NS1, NS2, or M2-2 may provide increased immunogenicity. As another strategy, the $\mathrm{F}$ and $\mathrm{G}$ genes were placed in promoter-proximal positions, which increased the level of expression of these protective antigens due to the transcriptional gradient (Krempl et al. 2002). This yielded a modest increase in immunogenicity in mice (Krempl et al. 2002). The level of expression of the $F$ and $G$ proteins also can be increased using versions of their genes that had been re-synthesized using codons optimal for translation, although our initial efforts have yielded only modest increases in expression (unpublished data). It also may be desirable to ablate the fractalkine motif in the $\mathrm{G}$ protein (Harcourt et al. 2006), or to eliminate expression of the secreted form of G (Bukreyev et al. 2008), since both of these features may contribute to reactogenicity and may interfere with the host immune response.

\section{Parainfluenza Viruses as RSV Vaccine Vectors}

Recombinant PIVs are being evaluated as vaccine vectors for expressing the RSV F and G glycoproteins, the two RSV neutralization antigens and major protective antigens. Using reverse genetics, the ORF for RSV F or G is placed under the control of a set of PIV genestart and gene-end transcription signals and is inserted as an extra gene into a suitably attenuated PIV genome and recovered as replication- competent virus. Priority is given to the RSV F protein because it is much more highly conserved among RSV strains than is the $\mathrm{G}$ protein, and because it was the more immunogenic and protective of the two antigens in studies in rodents (Connors et al. 1991). The clinical success of the RSV-F-specific monoclonal antibody palivizumab also supports the importance of the F protein as antigen.

The vectors that are being evaluated are HPIV1, HPIV2, HPIV3, and Sendai virus (SeV), the last being a murine relative of HPIV1 that shares considerable antigenic relatedness. HPIV1, 2, and 3 are significant pediatric pathogens, and thus the use of these viruses or related viruses as vectors creates a single vaccine virus capable of inducing immunity against two human pathogens: the PIV vector and RSV. HPIV3 is particularly appropriate as a vector for RSV immunization because both RSV and HPIV3 frequently infect young infants, and immunization against the two viruses should begin early in life. Also, the burden of disease associated with HPIV3 is substantially greater than with HPIV1 or 2, which more frequently cause illness in the preschool years. A bivalent vaccine against RSV and HPIV 3 could provide greater protection against viral LRI than a monovalent vaccine 
against RSV, and a bivalent vaccine based on a single virus can be developed more rapidly than a vaccine consisting of a mixture of two viruses.

A PIV-vectored RSV vaccine has a number of advantages for development, manufacture, and use compared to a live-attenuated RSV strain, specifically: (i) the PIVs replicate more efficiently in cell culture compared to RSV; (ii) RSV grown in cell culture mostly consists of large filamentous particles that are difficult to process, compared to the smaller, spherical particles of the PIVs; and (iii) the PIVs have substantially greater physical stability than RSV. The greater stability, in particular, would facilitate distribution and use in resourcelimited settings. Also, it has been speculated that RSV may substantially suppress or skew the host immune response, which provides another possible advantage of PIV vectors. Another potential advantage is that, since the RSV antigens are not involved in replication of the PIV vectors, versions of F or G can be expressed that have been engineered for improved immunogenicity but may have lost functionality, such as versions of RSV-F that have been stabilized in "post-fusion” or "pre-fusion” conformations (Magro et al. 2012; McLellan et al. 2011). Conversely, PIV vectors expressing RSV F and/or G protein have the disadvantage that only part of the RSV proteome is represented: while the presence of $F$ and G provides the viral neutralization antigens, the absence of the other proteins would mean the absence of a substantial portion of the epitopes for CD4+ and CD8+ T cells.

Initial studies with HPIV3 showed that the vector could accommodate three foreign genes totaling $7.5 \mathrm{~kb}$ (a nearly $50 \%$ increase in genome length) with only a minimal reduction in replication in cell culture (Skiadopoulos et al. 2000, 2002). In hamsters, the level of attenuation was positively correlated with the aggregate size of the foreign insert. Thus, the RSV insert confers attenuation in vivo, which must be taken into account when introducing attenuating mutations into the vector backbone. Furthermore, the level of attenuation conferred by the insert appeared to increase when in the presence of other attenuating mutations. The level of expression of a foreign insert was affected by its position in the genome: promoter-proximal inserts were expressed with greater efficiency, reflecting the viral transcriptional gradient. Initial studies indicated that the foreign genes appeared to be surprisingly stable: deletions were not observed, although chance point mutations were sometimes detected.

The first PIV vector to be developed for clinical evaluation was based on a chimeric virus called B/HPIV3 (Fig. 1, lower panel) that had been developed as an HPIV3 vaccine (Schmidt et al. 2002). This virus is based on BPIV3, which is attenuated in primates due to a natural host range restriction. In B/HPIV3, the BPIV3 F and $\mathrm{HN}$ genes were replaced by their counterparts in HPIV3. Thus, B/ HPIV3 combines the host range restriction of BPIV3 with the viral neutralization and major protective antigens of HPIV3. The determinants of the host range restriction of BPIV3 have been shown to be polygenic, and presumably involve the cumulative effect of multiple sequence differences. This likely accounts for the observed stability of the attenuation phenotype. An initial construct expressing the RSV G and $\mathrm{F}$ proteins together from promoter-proximal inserts appeared to be promising based on studies in rodents and African green monkeys (Schmidt et al. 2002). Subsequently, singleinsert constructs were evaluated to reduce the incidence of chance mutations incorporated in the RSV genes during replication. Chance mutations can accumulate in the added RSV 
genes because these are not involved in replication of the PIV vector, and thus there is no selective pressure against mutations. For example, the construct MEDI-534 (Fig. 1) was made in which the B/HPIV3 vector expresses the RSV F protein from an insert added between the $\mathrm{N}$ and $\mathrm{P}$ genes (Gomez et al. 2009; Tang et al. 2008). In seropositive children, this virus was well-tolerated and shedding was not detected (Gomez et al. 2009). In children seronegative to both RSV and HPIV3, MEDI-534 replicated in the majority of recipients, was well-tolerated, and induced a serum antibody response to RSV and HPIV3 in 50-55 \% and $100 \%$ of recipients, respectively (Bernstein et al. 2012). The percentage of recipients with a serum antibody response to RSV was substantially less than in previous studies in similar populations with live-attenuated RSV strains. Recent evaluation of MEDI-534 virus shed by seronegative children indicated that some isolates had genetic changes in the noncoding sequences of RSV F and/or in the RSV F ORF, which could lead to decreased expression of RSV F (Tang RS et al. 2012). Additional work is needed to improve the genetic stability and immunogenicity of this vaccine candidate.

HPIV1 and HPIV2 also are being developed as vectors for RSV F. The burden of RSV disease in children aged between 1 and 5 years highlights the need for reimmunization after the first year of life (Hall et al. 2009), and an HPIV1- or HPIV2-vectored RSV vaccine might be used to boost immunity in children previously immunized with an RSV vaccine. The use of an HPIV1- or HPIV2- vectored vaccine may be preferable to re-immunization with a live-attenuated RSV strain, because RSV-specific immunity from prior immunization would restrict replication of a live-attenuated RSV strain, but not that of an HPIV1 or HPIV2 vector. This has been confirmed in studies in rodents, in which secondary immunization of RSV-immune animals with an HPIV1-RSV-F virus was more immunogenic than re-immunization with a live-attenuated RSV strain (unpublished data). In the case of HPIV1 and HPIV2 vectors, it will be necessary to develop suitably attenuated backbones. A number of attenuating mutations for HPIV1 and HPIV2 have been characterized (Bartlett et al. 2005; Nolan et al. 2007) and attenuated versions of HPIV1 and HPIV2 are presently in clinical studies in seropositive and seronegative children (ClinicalTrials.gov identifiers NCT00641017 and NCT01139437, respectively).

Sendai virus $(\mathrm{SeV})$, the murine relative of HPIV1, also is being evaluated as a vaccine vector for human use. Immunization of experimental animals with $\mathrm{SeV}$ was protective against challenge with HPIV1, reflecting the antigenic relatedness of the two viruses. $\mathrm{SeV}$ may be attenuated in humans due to a host range restriction, although this was not evident in studies in non-human primates (Skiadopoulos et al. 2002). Shedding of $\mathrm{SeV}$ was not detected in HPIV1-seropositive human adults, which is consistent with attenuation (Slobod et al. 2004). SeV is presently being evaluated for safety and immunogenicity in children and toddlers >12 months of age (Clinicaltrials.gov identifier NCT00186927). In preclinical studies, $\mathrm{SeV}$ has been engineered to express a number of glycoproteins from other paramyxoviruses including the RSV F and G proteins. SeV expressing the RSV F or G protein was immunogenic and protective against RSV challenge in cotton rats, and $\mathrm{SeV}$ expressing RSV F was immunogenic and protective in African green monkeys (Jones et al. 2012). It is anticipated that an SeV-RSV F construct will be evaluated in clinical trials once the safety of the parent $\mathrm{SeV}$ in young children has been established. 


\section{Lessons Learned from the Evaluation of Live-Attenuated RSV Vaccines}

As biologically derived and recombinant live-attenuated RSV vaccines have been evaluated over the past two decades, certain principles have emerged which can be used to guide future development and evaluation of live-attenuated vaccine candidates:

1. Substantial replication in adults or RSV-seropositive children is a marker of insufficient attenuation for RSV-seronegative children and RSV-nä̈ve infants. Initial evaluation of a $10^{5} \mathrm{TCID}_{50}$ dose of $c$ ts $248 / 955$ in RSV-seropositive children demonstrated that this virus replicated in $38 \%$ of vaccinees for a mean duration of 5 days and at a mean peak titer of $10^{2.7} \mathrm{TCID}_{50} / \mathrm{mL}$. This vaccine appeared to be well-tolerated. However, in RSV-seronegative children, cpts248/955 was minimally restricted in replication (mean peak titer, $10^{4.4} \mathrm{TCID}_{50} / \mathrm{mL}$; mean duration of replication, 9 days), and was associated with fever or lower respiratory tract illness (Table 1; Karron et al. 1997). Thus, prolonged, substantial replication of a live-attenuated RSV vaccine candidate in RSV-experienced populations, even if well-tolerated, is an indication that the vaccine may be insufficiently attenuated for RSV-naïve populations. In contrast, vaccine candidates with a greater level of attenuation, such as cpts248/404 and cpts248/404/1030/ $\Delta \mathrm{SH}$, could only be recovered sporadically or not at all from nasal washes of RSV-seropositive children, and were infectious, welltolerated, and immunogenic in seronegative children (Table 2; Karron et al. 2005; Wright et al. 2000). Thus, new vaccine candidates are typically evaluated sequentially in adults and RSV-seropositive children, and minimal or no virus shedding in these RSV-experienced groups is a necessary signal that the vaccine can proceed to evaluation in seronegative children. A corollary of this principle is that a live-attenuated RSV vaccine that is satisfactorily attenuated for RSV-naïve children will be over-attenuated for adults and older children, underscoring the need for alternative vaccine strategies for these populations.

2. In children over 6 months of age, a serum RSV neutralizing antibody titer of $\leq 1: 40$, as measured in a classic complement-enhanced $60 \%$ plaque reduction neutralization assay, is a useful determinant of susceptibility to infection with highly attenuated live RSV vaccine viruses. While this titer was initially chosen empirically, based upon the range of antibody titers measured in young children, it has proved to be a reliable predictor of infectivity with highly attenuated RSV vaccine candidates such as cpts248/404 (Wright et al. 2000), rA2cp28/404/ $\mathrm{SH}$, rA2cp28/404/1030/ $\Delta \mathrm{SH}$ (Karron et al. 2005; Wright et al. 2000) and rRSV MEDI $\triangle \mathrm{M} 2-2$ (unpublished observations). We therefore define RSV "seropositive" as children $>6$ months of age with neutralizing antibody titers $>1: 40$, and "seronegative" as those with neutralizing antibody titers $\leq: 40$. If other assays that measure RSV neutralizing activity are used in future clinical trials, cut-off values will need to be established.

3. Maternally derived RSV neutralizing antibody does not interfere with replication of live-attenuated RSV vaccines in the upper respiratory tract of young infants. cpts248/404 and 248/404/1030/ $\Delta \mathrm{SH}$ have both been evaluated in 1-2 month-old 
infants, who were presumed to be RSV-naïve but have residual maternally derived antibody. For each virus, comparison of peak viral titers in nasal wash specimens demonstrated levels of vaccine virus replication in young infants that were equal to or greater than those observed in RSV-seronegative 6-24 month-old children, indicating a lack of restriction of replication by maternal antibody (Table 3; Karron et al. 2005; Wright et al. 2000). This finding is particularly important as vaccination strategies that incorporate both maternal and infant immunization are contemplated.

4. Restriction of a second dose 'challenge' with intranasally administered vaccine virus demonstrates that young infants can develop protective immunity even in the absence of a measurable antibody response. As noted above, intranasally delivered respiratory viruses replicate in the upper respiratory tracts of young infants even in the presence of maternal antibody. However, passive antibody has been shown to suppress humoral responses in these young infants (Murphy et al. 1986), which may occur through epitope masking or other immunologic mechanisms. Nonetheless, immunity capable of restricting viral replication can be induced in these situations, and this is best measured by administering a second 'challenge' dose of the vaccine virus. As an example, replication of the second dose of the investigational vaccine virus $\mathrm{rA} 2 \mathrm{cp} 28 / 404 / 1030 / \Delta \mathrm{SH}$ was restricted approximately 100-fold compared to replication of the first dose in 1-3 month-old infants (Karron et al. 2005). This finding underscores the utility of a 'challenge' dose for assessment of induction of immunity, but also highlights the need for development of additional assays for measurement of immune responses in young infants.

\section{Conclusions: The Future of Live-Attenuated RSV Vaccine Development}

The live-attenuated approach continues to offer a number of advantages for development of an RSV vaccine for RSV-naive infants and young children. The most important advantage is the lack of disease enhancement associated with live RSV vaccines. Also, as previously noted, live-attenuated respiratory virus vaccines generally induce broad and durable immunity in infants and young children. In addition, the administration of a live-attenuated RSV vaccine should prime a young infant for development of a protective and nonpathologic immune response, and therefore could be safely followed by administration of a non-replicating RSV vaccine. The availability of reverse genetics and a panel of characterized attenuating mutations has led to the systematic development of a number of live-attenuated RSV vaccine candidates, including rA2cp248/404/ 1030 $\Delta \mathrm{SH}$, the first vaccine candidate that appeared to be well-tolerated and moderately immunogenic in phase I trials in infants as young as 1 month of age (Karron et al. 2005).

One potential limitation of live-attenuated RSV vaccines is that the level of viral replication is generally linked to the magnitude of the antibody response, and it might therefore be difficult to achieve a balance between the level of viral replication required for safety and the level required for induction of protective immunity. However, improved understanding of RSV gene function has allowed for the development of new recombinant vaccine candidates that may de-link replication and immune response, either by enhancing antigen production while limiting viral replication ( $\Delta \mathrm{M} 2-2$ deletion), or by bolstering the innate 
immune response ( $\triangle \mathrm{NS} 2$ deletion). Clinical evaluation of these promising vaccine candidates is underway.

\section{Acknowledgments}

PLC and UJB were supported by the Intramural Research Program of NIAID, NIH. RAK was supported by NIAID contract HHSN272200900010C.

\section{References}

Ambrose CS, Wu X, Belshe RB. The efficacy of live attenuated and inactivated influenza vaccines in children as a function of time postvaccination. Pediatr Infect Dis J. 2010; 29:806-811. [PubMed: 20458256]

Ambrose CS, Levin MJ, Belshe RB. The relative efficacy of trivalent live attenuated and inactivated influenza vaccines in children and adults. Influenza Respir Viruses. 2011; 5:67-75.

Bartlett EJ, Amaro-Carambot E, Surman SR, Newman JT, Collins PL, Murphy BR, Skiadopoulos MH. Human parainfluenza virus type I (HPIV1) vaccine candidates designed by reverse genetics are attenuated and efficacious in African green monkeys. Vaccine. 2005; 23:4631-4646. [PubMed: 15951066]

Belshe RB, Edwards KM, Vesikari T, Black SV, Walker RE, Hultquist M, Kemble G, Connor EM. Live attenuated versus inactivated influenza vaccine in infants and young children. $\mathrm{N}$ Engl J Med. 2007; 356:685-696. [PubMed: 17301299]

Bermingham A, Collins PL. The M2-2 protein of human respiratory syncytial virus is a regulatory factor involved in the balance between RNA replication and transcription. Proc Natl Acad Sci U S A. 1999; 96:11259-11264. [PubMed: 10500164]

Bernstein DI, Malkin E, Abughali N, Falloon J, Yi T, Dubovsky F. Phase 1 study of the safety and immunogenicity of a live, attenuated respiratory syncytial virus and parainfluenza virus type 3 vaccine in seronegative children. Pediatr Infect Dis J. 2012; 31:109-114. [PubMed: 21926667]

Bitko V, Shulyayeva O, Mazumder B, Musiyenko A, Ramaswamy M, Look DC, Barik S. Nonstructural proteins of respiratory syncytial virus suppress premature apoptosis by an NFkappaB- dependent, interferon-independent mechanism and facilitate virus growth. J Virol. 2007; 81:1786-1795. [PubMed: 17151097]

Buchholz UJ, Granzow H, Schuldt K, Whitehead SS, Murphy BR, Collins PL. Chimeric bovine respiratory syncytial virus with glycoprotein gene substitutions from human respiratory syncytial virus (HRSV): Effects on host range and evaluation as a live-attenuated HRSV vaccine. J Virol. 2000; 74:1187-1199. [PubMed: 10627529]

Bukreyev A, Yang L, Fricke J, Cheng L, Ward JM, Murphy BR, Collins PL. The secreted form of respiratory syncytial virus $G$ glycoprotein helps the virus evade antibody-mediated restriction of replication by acting as an antigen decoy and through effects on Fc receptor-bearing leukocytes. $\mathrm{J}$ Virol. 2008; 82:12191-12204. [PubMed: 18842713]

Collins PL, Murphy BR. New generation live vaccines against human respiratory syncytial virus designed by reverse genetics. Proc Am Thorac Soc. 2005; 2:166-173. [PubMed: 16113487]

Connors M, Collins PL, Firestone CY, Murphy BR. Respiratory syncytial virus (RSV) F, G, M2 (22 $\mathrm{K})$, and N proteins each induce resistance to RSV challenge, but resistance induced by M2 and N proteins is relatively short-lived. J Virol. 1991; 65:1634-1637. [PubMed: 1995956]

Crowe JE Jr, Bui PT, London WT, Davis AR, Hung PP, Chanock RM, Murphy BR. Satisfactorily attenuated and protective mutants derived from a partially attenuated cold-passaged respiratory syncytial virus mutant by introduction of additional attenuating mutations during chemical mutagenesis. Vaccine. 1994; 12:691-699. [PubMed: 8091846]

Crowe JE Jr, Bui PT, Siber GR, Elkins WR, Chanock RM, Murphy BR. Cold-passaged, temperaturesensitive mutants of human respiratory syncytial virus (RSV) are highly attenuated, immunogenic, and protective in seronegative chimpanzees, even when RSV antibodies are infused shortly before immunization. Vaccine. 1995; 13:847-855. [PubMed: 7483808] 
Firestone CY, Whitehead SS, Collins PL, Murphy BR, Crowe JE Jr. Nucleotide sequence analysis of the respiratory syncytial virus subgroup A cold-passaged (cp) temperature sensitive (ts) cpts-248/404 live attenuated virus vaccine candidate. Virology. 1996; 225:419-422. [PubMed: 8918930]

Friedewald WT, Forsyth BR, Smith CB, Gharpure MA, Chanock RM. Low-temperature-grown RS virus in adult volunteers. JAMA. 1968; 203:690-694. [PubMed: 5694511]

Fuentes S, Tran KC, Luthra P, Teng MN, He B. Function of the respiratory syncytial virus small hydrophobic protein. J Virol. 2007; 81:8361-8366. [PubMed: 17494063]

Gharpure MA, Wright PF, Chanock RM. Temperature-sensitive mutants of respiratory syncytial virus. J Virol. 1969; 3:414-421. [PubMed: 4890619]

Gomez M, Mufson MA, Dubovsky F, Knightly C, Zeng W, Losonsky G. Phase-I study MEDI-534, of a live, attenuated intranasal vaccine against respiratory syncytial virus and parainfluenza-3 virus in seropositive children. Pediatr Infect Dis J. 2009; 28:655-658. [PubMed: 19483659]

Gonzalez IM, Karron RA, Eichelberger M, Walsh EE, Delagarza VW, Bennett R, Chanock RM, Murphy BR, Clements-Mann ML, Falsey AR. Evaluation of the live attenuated cpts 248/404 RSV vaccine in combination with a subunit RSV vaccine (PFP-2) in healthy young and older adults. Vaccine. 2000; 18:1763-1772. [PubMed: 10699324]

Hall CB, Weinberg GA, Iwane MK, Blumkin AK, Edwards KM, Staat MA, Auinger P, Griffin MR, Poehling KA, Erdman D, Grijalva CG, Zhu Y, Szilagyi P. The burden of respiratory syncytial virus infection in young children. N Engl J Med. 2009; 360:588-598. [PubMed: 19196675]

Harcourt J, Alvarez R, Jones LP, Henderson C, Anderson LJ, Tripp RA. Respiratory syncytial virus G protein and $\mathrm{G}$ protein $\mathrm{CX} 3 \mathrm{C}$ motif adversely affect CX3CR1+ T cell responses. J Immunol. 2006; 176:1600-1608. [PubMed: 16424189]

Hoft DF, Babusis E, Worku S, Spencer CT, Lottenbach K, Truscott SM, Abate G, Sakala IG, Edwards KM, Creech CB, Gerber MA, Bernstein DI, Newman F, Graham I, Anderson EL, Belshe RB. Live and inactivated influenza vaccines induce similar humoral responses, but only live vaccines induce diverse T-cell responses in young children. J Infect Dis. 2011; 204:845-853. [PubMed: 21846636]

Jin H, Clarke D, Zhou HZ, Cheng X, Coelingh K, Bryant M, Li S. Recombinant human respiratory syncytial virus (RSV) from cDNA and construction of subgroup A and B chimeric RSV. Virology. 1998; 251:206-214. [PubMed: 9813216]

Jones BG, Sealy RE, Rudraraju R, Traina-Dorge VL, Finneyfrock B, Cook A, Takimoto T, Portner A, Hurwitz JL. Sendai virus-based RSV vaccine protects African green monkeys from RSV infection. Vaccine. 2012; 30:959-968. [PubMed: 22119594]

Juhasz K, Whitehead SS, Boulanger CA, Firestone CY, Collins PL, Murphy BR. The two amino acid substitutions in the L protein of cpts530/1009, a live-attenuated respiratory syncytial virus candidate vaccine, are independent temperature-sensitive and attenuation mutations. Vaccine. 1999; 17:1416-1424. [PubMed: 10195777]

Karron RA, Buonagurio DA, Georgiu AF, Whitehead SS, Adamus JE, Clements-Mann ML, Harris DO, Randolph VB, Udem SA, Murphy BR, Sidhu MS. Respiratory syncytial virus (RSV) SH and $G$ proteins are not essential for viral replication in vitro: clinical evaluation and molecular characterization of a cold-passaged, attenuated RSV subgroup B mutant. Proc Natl Acad Sci U S A. 1997a; 94:13961-13966. [PubMed: 9391135]

Karron RA, Wright PF, Crowe JE Jr, Clements ML, Thompson J, Makhene M, Casey R, Murphy BR. Evaluation of two live, cold-passaged, temperature-sensitive respiratory syncytial virus (RSV) vaccines in chimpanzees, adults, infants and children. J Infect Dis. 1997b; 176:1428-1436. [PubMed: 9395351]

Karron RA, Wright PF, Belshe RB, Thumar B, Casey R, Newman F, Polack FP, Randolph VB, Deatly A, Hackell J, Gruber W, Murphy BR, Collins PL. Identification of a recombinant live attenuated respiratory syncytial virus vaccine candidate that is highly attenuated in infants. J Infect Dis. 2005; 191:1093-1104. [PubMed: 15747245]

Kim HW, Arrobio JO, Pyles G, Brandt CD, Camargo E, Chanock RM, Parrott RH. Clinical and immunological response of infants and children to administration of low-temperature adapted respiratory syncytial virus. Pediatrics. 1971; 48:745-755. [PubMed: 4330595] 
Kim HW, Arrobio JO, Brandt CD, Wright P, Hodes D, Chanock RM, Parrott RH. Safety and antigenicity of temperature sensitive (TS) mutant respiratory syncytial virus (RSV) in infants and children. Pediatrics. 1973; 52:56-63. [PubMed: 4353352]

Krempl C, Murphy BR, Collins PL. Recombinant respiratory syncytial virus with the G and F genes shifted to the promoter-proximal positions. J Virol. 2002; 76:11931-11942. [PubMed: 12414935]

Luongo C, Yang L, Winter CC, Spann KM, Murphy BR, Collins PL, Buchholz UJ. Codon stabilization analysis of the " 248 " temperature sensitive mutation for increased phenotypic stability of respiratory syncytial virus vaccine candidates. Vaccine. 2009; 27:5667-5676. [PubMed: 19646406]

Luongo C, Winter CC, Collins PL, Buchholz UJ. Increased genetic and phenotypic stability of a promising live-attenuated respiratory syncytial virus vaccine candidate by reverse genetics. $\mathbf{J}$ Virol. 2012; 86:10792-10804. [PubMed: 22837193]

Luongo C, Winter CC, Collins PL, Buchholz UJ. Respiratory syncytial virus modified by deletions of the NS2 gene and amino acid S1313 of the L polymerase protein is a temperature-sensitive, liveattenuated vaccine candidate that is phenotypically stable a physiologic temperature. J Virol. 2013; 87:1985-1996. [PubMed: 23236065]

Magro M, Mas V, Chappell K, Vazquez M, Cano O, Luque D, Terron MC, Melero JA, Palomo C. Neutralizing antibodies against the preactive form of respiratory syncytial virus fusion protein offer unique possibilities for clinical intervention. Proc Natl Acad Sci USA. 2012; 109:3089-3094. [PubMed: 22323598]

McKay E, Higgins P, Tyrrell D, Pringle C. Immunogenicity and pathogenicity of temperature-sensitive modified respiratory syncytial virus in adult volunteers. J Med Virol. 1988; 25:411-421. [PubMed: 3171557]

McLellan JS, Yang Y, Graham BS, Kwong PD. Structure of the respiratory syncytial virus fusion glycoprotein in the post-fusion conformation reveals preservation of neutralizing epitopes. J Virol. 2011; 85:7788-7796. [PubMed: 21613394]

Murphy BR, Collins PL. Live-attenuated virus vaccines for respiratory syncytial and parainfluenza viruses: applications of reverse genetics. J Clin Invest. 2002; 110:21-27. [PubMed: 12093883]

Murphy BR, Graham BS, Prince GA, Walsh EE, Chanock RM, Karzon DT, Wright PF. Serum and nasal-wash immunoglobulin $\mathrm{G}$ and $\mathrm{A}$ antibody response of infants and children to respiratory syncytial virus F and G glycoproteins following primary infection. J Clin Microbiol. 1986; 23:1009-1014. [PubMed: 3754878]

Nolan SM, Skiadopoulos MH, Bradley K, Kim OS, Bier S, Amaro-Carambot E, Surman SR, Davis S, St Claire M, Elkins R, Collins PL, Murphy BR, Schaap-Nutt A. Recombinant human parainfluenza virus type 2 vaccine candidates containing a $3^{\prime}$ genomic promoter mutation and $\mathrm{L}$ polymerase mutations are attenuated and protective in non-human primates. Vaccine. 2007; 25:6409-6422. [PubMed: 17658669]

Pringle CR, Filipiuk AH, Robinson BS, Watt PJ, Higgins P, Tyrrell DA. Immunogenicity and pathogenicity of a triple temperature-sensitive modified respiratory syncytial virus in adult volunteers. Vaccine. 1993; 11:473-478. [PubMed: 8470433]

Schmidt AC, Wenzke DR, McAuliffe JM, St Clair M, Elkins WR, Murphy BR, Collins PL. Mucosal immunization of rhesus monkeys against respiratory syncytial virus subgroups $\mathrm{A}$ and $\mathrm{B}$ and human parainfluenza virus type 3 using a live cDNA-derived vaccine based on a host rangeattenuated bovine parainfluenza virus type 3 vector backbone. J Virol. 2002; 76:1089-1099. [PubMed: 11773385]

Skiadopoulos MH, Surman SR, Durbin AP, Collins PL, Murphy BR. Long nucleotide insertions between the $\mathrm{HN}$ and $\mathrm{L}$ protein coding regions of human parainfluenza virus type 3 yield viruses with temperature-sensitive and attenuation phenotypes. Virology. 2000; 272:225-234. [PubMed: 10873765]

Skiadopoulos MH, Surman SR, Riggs JM, Elkins WR, St Claire M, Nishio M, Garcin D, Kolakofsky D, Collins PL, Murphy BR. Sendai virus, a murine parainfluenza virus type 1, replicates to a level similar to human PIV1 in the upper and lower respiratory tract of African green monkeys and chimpanzees. Virology. 2002a; 297:153-160. [PubMed: 12083845] 
Skiadopoulos MH, Surman SR, Riggs JM, Orvell C, Collins PL, Murphy BR. Evaluation of the replication and immunogenicity of recombinant human parainfluenza virus type 3 vectors expressing up to three foreign glycoproteins. Virology. 2002b; 297:136-152. [PubMed: 12083844]

Slobod KS, Shenep JL, Lujan-Zilbermann J, Allison K, Brown B, Scroggs RA, Portner A, Coleclough C, Hurwitz JL. Safety and immunogenicity of intranasal murine parainfluenza virus type 1 (Sendai virus) in healthy human adults. Vaccine. 2004; 22:3182-3186. [PubMed: 15297072]

Surman SR, Collins PL, Murphy BR, Skiadopoulos MH. An improved method for the recovery of recombinant paramyxovirus vaccine candidates suitable for use in human clinical trials. J Virol Methods. 2007; 141:30-33. [PubMed: 17210187]

Tang, RS.; ME; Stillman, E.; Nelson, C.; Yang, C.; Song, E.; Liang, B.; Shambaugh, C.; Zuo, F.; Liem, A.; Balagot, C.; Wang, K.; Galinski, M.; Esser, M. Implication of genetic changes observed in Phase I evaluation of MEDI-534, a live attenuated chimeric bovine human parainfluenza type 3 vectored RSV vaccine. Poster \#38, RSV; 2012; Santa FE, MN. 2012.

Tang RS, Nguyen N, Zhou H, Jin H. Clustered charge-to-alanine mutagenesis of human respiratory syncytial virus L polymerase generates temperature-sensitive viruses. Virology. 2002; 302:207216. [PubMed: 12429529]

Tang RS, Spaete RR, Thompson MW, MacPhail M, Guzzetta JM, Ryan PC, Reisinger K, Chandler P, Hilty M, Walker RE, Gomez MM, Losonsky GA. Development of a PIV-vectored RSV vaccine: preclinical evaluation of safety, toxicity, and enhanced disease and initial clinical testing in healthy adults. Vaccine. 2008; 26:6373-6382. [PubMed: 18822334]

Teng MN, Whitehead SS, Bermingham A, Clair MS, Elkins WR, Murphy BR, Collins PL. Recombinant respiratory syncytial virus that does not express the NS1 or M2-2 protein is highly attenuated and immunogenic in chimpanzees. J Virol. 2000; 74:9317-9321. [PubMed: 10982380]

Valarcher JF, Furze J, Wyld S, Cook R, Conzelmann KK, Taylor G. Role of alpha/beta interferons in the attenuation and immunogenicity of recombinant bovine respiratory syncytial viruses lacking NS proteins. J Virol. 2003; 77:8426-8439. [PubMed: 12857912]

Waris ME, Tsou C, Erdman DD, Day DB, Anderson LJ. Priming with live respiratory syncytial virus (RSV) prevents the enhanced pulmonary inflammatory response seen after RSV challenge in BALB/c mice immunized with formalin-inactivated RSV. J Virol. 1997; 71:6935-6939. [PubMed: 9261421]

Watt PJ, Robinson BS, Pringle CR, Tyrrell DA. Determinants of susceptibility to challenge and the antibody response of adult volunteers given experimental respiratory syncytial virus vaccines. Vaccine. 1990; 8:231-236. [PubMed: 2363300]

Whitehead SS, Firestone CY, Collins PL, Murphy BR. A single nucleotide substitution in the transcription start signal of the M2 gene of respiratory syncytial virus vaccine candidate cpts248/404 is the major determinant of the temperature-sensitive and attenuation phenotypes. Virology. 1998a; 247:232-239. [PubMed: 9705916]

Whitehead SS, Juhasz K, Firestone CY, Collins PL, Murphy BR. Recombinant respiratory syncytial virus (RSV) bearing a set of mutations from cold-passaged RSV is attenuated in chimpanzees. $\mathrm{J}$ Virol. 1998b; 72:4467-4471. [PubMed: 9557743]

Whitehead SS, Bukreyev A, Teng MN, Firestone CY, St Claire M, Elkins WR, Collins PL, Murphy BR. Recombinant respiratory syncytial virus bearing a deletion of either the NS2 or SH gene is attenuated in chimpanzees. J Virol. 1999a; 73:3438-3442. [PubMed: 10074199]

Whitehead SS, Firestone CY, Karron RA, Crowe JE Jr, Elkins WR, Collins PL, Murphy BR. Addition of a missense mutation present in the L gene of respiratory syncytial virus (RSV) cpts530/1030 to RSV vaccine candidate cpts248/404 increases its attenuation and temperature sensitivity. J Virol. 1999b; 73:871-877. [PubMed: 9882287]

Whitehead SS, Hill MG, Firestone CY, St Claire M, Elkins WR, Murphy BR, Collins PL. Replacement of the $\mathrm{F}$ and $\mathrm{G}$ proteins of respiratory syncytial virus (RSV) subgroup A with those of subgroup B generates chimeric live attenuated RSV subgroup B vaccine candidates. J Virol. 1999c; 73:9773-9780. [PubMed: 10559287]

Wright PF, Mills Jv, Chanock RM. Evaluation of a temperature-sensitive mutant of respiratory syncytial virus in adults. J Infect Dis. 1971; 124:505-511. [PubMed: 4940177] 
Wright PF, Shinozaki T, Fleet W, Sell SH, Thompson J, Karzon DT. Evaluation of a live, attenuated respiratory syncytial virus vaccine in infants. J Pediatr. 1976; 88:931-936. [PubMed: 178852]

Wright PF, Belshe RB, Kim HW, Van Voris LP, Chanock RM. Administration of a highly attenuated, live respiratory syncytial virus vaccine to adults and children. Infect Immun. 1982; 37:397-400. [PubMed: 7107009]

Wright PF, Karron RA, Belshe RB, Thompson J, Crowe JE Jr, Boyce TG, Halburnt LL, Reed GW, Whitehead SS, Anderson EL, Wittek AE, Casey R, Eichelberger M, Thumar B, Randolph VB, Udem SA, Chanock RM, Murphy BR. Evaluation of a live, cold-passaged, temperature-sensitive, respiratory syncytial virus vaccine candidate in infancy. J Infect Dis. 2000; 182:1331-1342. [PubMed: 11010838]

Wright PF, Karron RA, Madhi SA, Treanor JJ, King JC, O'Shea A, Ikizler MR, Zhu Y, Collins PL, Cutland C, Randolph VB, Deatly AM, Hackell JG, Gruber WC, Murphy BR. The interferon antagonist NS2 protein of respiratory syncytial virus is an important virulence determinant for humans. J Infect Dis. 2006; 193:573-581. [PubMed: 16425137]

Wright PF, Karron RA, Belshe RB, Shi JR, Randolph VB, Collins PL, O’Shea AF, Gruber WC, Murphy BR. The absence of enhanced disease with wild type respiratory syncytial virus infection occurring after receipt of live, attenuated, respiratory syncytial virus vaccines. Vaccine. 2007; 25:7372-7378. [PubMed: 17868959]

Zhang W, Choi Y, Haynes LM, Harcourt JL, Anderson LJ, Jones LP, Tripp RA. Vaccination to induce antibodies blocking the CX3C-CX3CR1 interaction of respiratory syncytial virus $\mathrm{G}$ protein reduces pulmonary inflammation and virus replication in mice. J Virol. 2010; 84:1148-1157. [PubMed: 19864390] 
rA2cp248/404/1030 $\Delta$ SH (and MEDI-559)

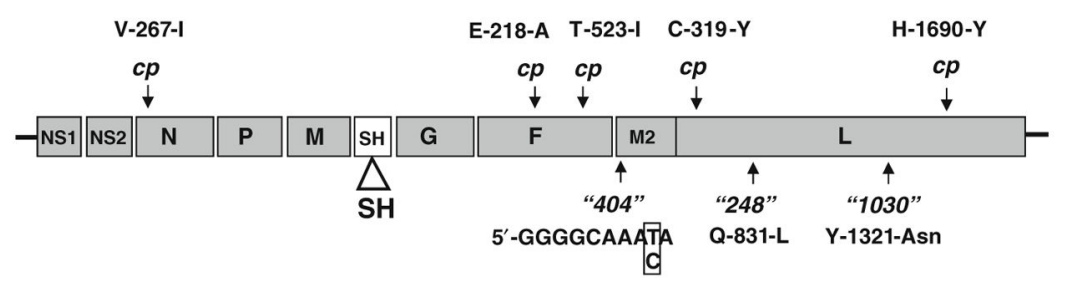

MEDI -534

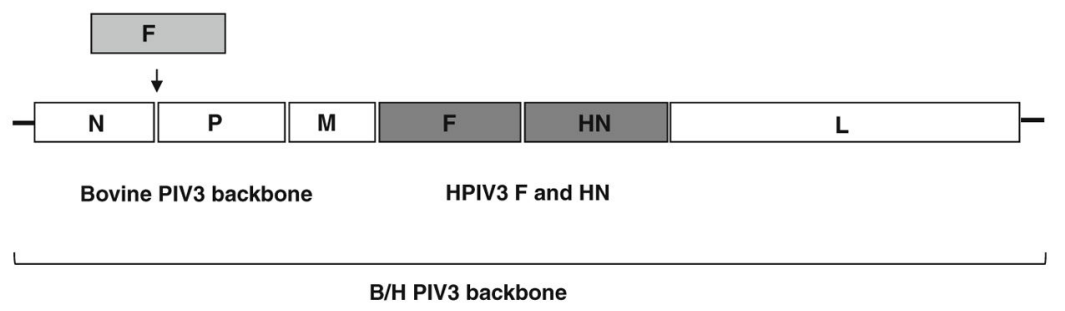

Fig. 1.

Two types of live RSV candidate vaccines made by reverse genetics that have been evaluated clinically. The rA2cp248/404/1030 $\Delta$ SH virus (upper panel) represents the strategy of developing an attenuated derivative of WT RSV. This mutant contains five coldpassaged (cp) mutations in the N, F, and L proteins, two amino acid substitutions (248 and 1030) in L, and one nucleotide substitution in the M2 GS signal (404) that independently confer temperature-sensitivity, and deletion of the SH gene. This virus was previously shown to be well-tolerated and immunogenic in infants and young children (Karron et al. 2005). MEDI-559 is another version of this virus that differs by a number of silent mutations and is phenotypically indistinguishable from rA2cp248/404/1030 $\Delta \mathrm{SH}$. As noted in the text, MEDI-559 is currently being evaluated in a phase I-II clinical trial. The MEDI-534 virus (lower panel) represents the strategy of using a parainfluenza virus vector to express RSV antigen, in this case the RSV F protein, to provide a bivalent vaccine against RSV and HPIV3. MEDI-534 is a chimeric virus in which the F and HN genes from BPIV3 have been replaced by their counterparts from HPIV3 and the coding sequence for the RSV F gene was placed under the control of HPIV3 transcription signals and inserted as an added gene between the $\mathrm{N}$ and $\mathrm{P}$ genes. This virus also has been evaluated in clinical studies (Bernstein et al. 2012; Gomez et al. 2009; Tang RS 2012; Tang et al. 2008) 


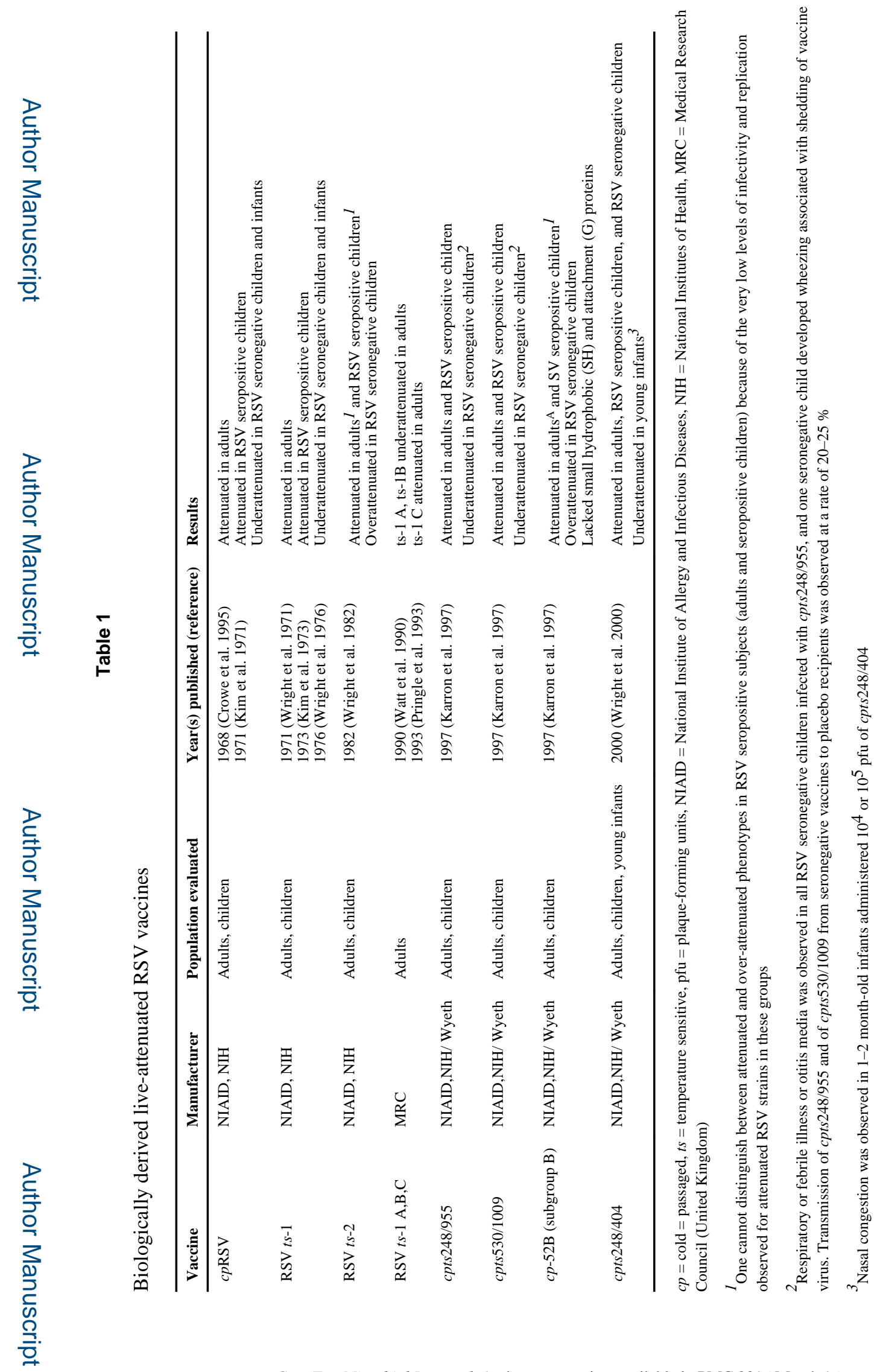

Curr Top Microbiol Immunol. Author manuscript; available in PMC 2016 March 16. 


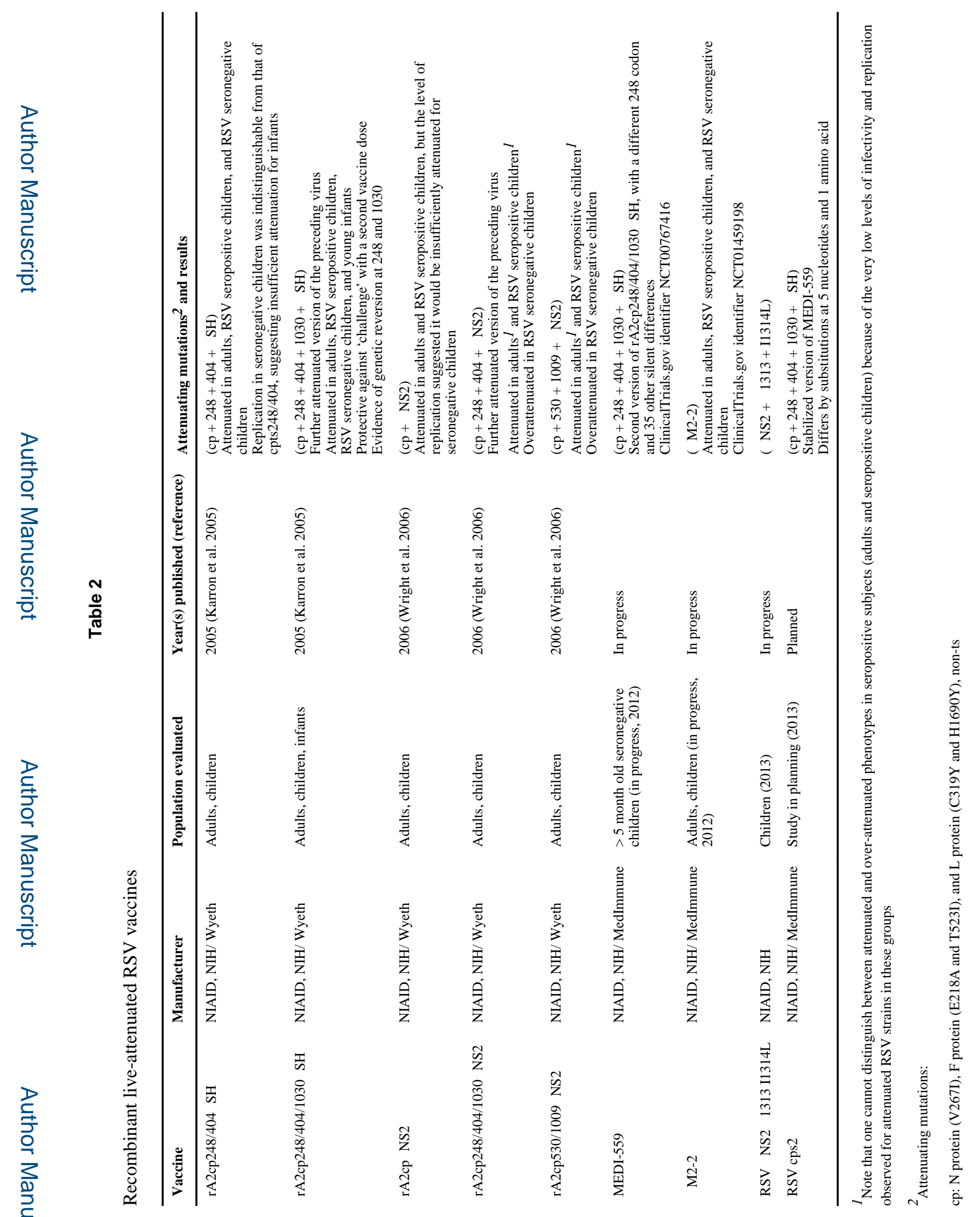

Curr Top Microbiol Immunol. Author manuscript; available in PMC 2016 March 16. 


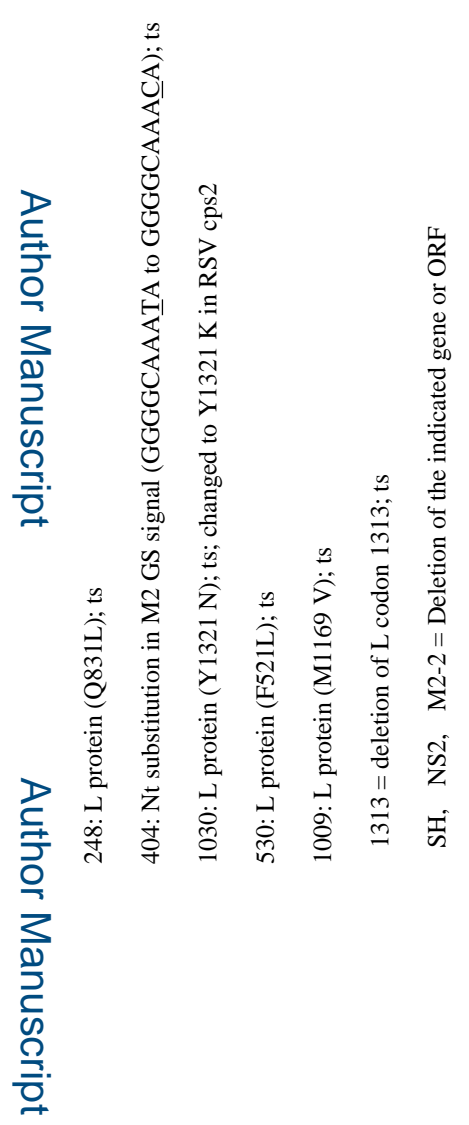

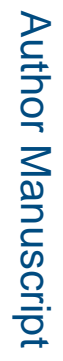

D

Curr Top Microbiol Immunol. Author manuscript; available in PMC 2016 March 16. 
Table 3

Replication of live-attenuated RSV vaccines is comparable in infants and young children

\begin{tabular}{|c|c|c|c|c|}
\hline Vaccine & Dose $\left(\log _{10} \mathrm{PFU} / \mathrm{mL}\right)$ & Population evaluated & No. of subjects & $\begin{array}{l}\text { Mean peak titer shed } \\
\left(\log _{10} \mathrm{PFU} / \mathrm{mL}\right)\end{array}$ \\
\hline \multirow[t]{4}{*}{ cpts $248 / 404^{l}$} & 4.0 & Seronegative children 6-24 months old & 11 & 2.4 \\
\hline & 4.0 & Infants $1-2$ months old & 7 & 4.2 \\
\hline & 5.0 & Seronegative children 6-24 months old & 38 & 4.2 \\
\hline & 5.0 & Infants $1-2$ months old & 17 & 4.0 \\
\hline \multirow[t]{4}{*}{$\mathrm{rA} 2 \mathrm{cp} 248 / 404 / 1030 \Delta \mathrm{SH}^{2}$} & 4.3 & Seronegative children 6-24 months old & 13 & 2.6 \\
\hline & 4.3 & Infants $1-2$ months old & 16 & 2.4 \\
\hline & 5.3 & Seronegative children 6-24 months old & 8 & 2.5 \\
\hline & 5.3 & Infants $1-2$ months old & 16 & 3.5 \\
\hline
\end{tabular}

${ }^{1}$ Ref. (Wright et al. 2000)

2 Ref. (Karron et al. 2005) 